\title{
Role of some MiRNA affecting polycystic ovarian syndrome and SIRT1 levels
}

\author{
Nida Farooqui \\ Aga Khan University, nida.farooqui@aku.edu \\ Quratulain Maha \\ Aga Khan University, quratulain.maha@scholar.aku.edu \\ Rehana Rehman \\ Aga Khan University, rehana.rehman@aku.edu
}

Follow this and additional works at: https://ecommons.aku.edu/pakistan_fhs_mc_bbs

Part of the Life Sciences Commons

\section{Recommended Citation}

Farooqui, N., Maha, Q., Rehman, R. (2020). Role of some MiRNA affecting polycystic ovarian syndrome and SIRT1 levels. JPMA. The Journal of the Pakistan Medical Association, 70(5), 945-945.

Available at: https://ecommons.aku.edu/pakistan_fhs_mc_bbs/842 
LETTER TO THEEDITOR

\section{Role of some MiRNA Affecting Polycystic Ovarian Syndrome and SIRT1 levels}

Nida Farooqui, Qurat-ul-ain Maha, Rehana Rehman

Dear Editor, Polycystic Ovarian Syndrome (PCOS) is an ovarian dysfunction with clinical manifestations such as menstrual irregularities, signs of hyperandrogenaemia, obesity and because of hyperinsulinaemia, risk of developing type 2 diabetes mellitus. PCOS development also include genetic, environmental and lifestyle factors. ${ }^{1}$

Sirtuin 1 (SIRT1) is an NAD+ -dependent deacetylase protein that plays an important role in cellular/metabolic stress or gene injury. ${ }^{2}$ As PCOS is a physiological dysfunction associated with inflammation, immune system and insulin metabolism, SIRT1 levels have been observed higher in PCOS patients than in a healthy person. ${ }^{3}$ MiRNAs are nucleotide regulatory RNAs and its activation helps for transition of a cell from one state to another therefore playing a critical role in many cells such as cell proliferation, development, survival and apoptosis particularly in the granulosa cells of the ovary. ${ }^{4}$ In some metabolic diseases miRNA are highly expressed revealing them as a target to study for diseases associated with SIRT1 dysfunction and PCOs (Figure). Therefore any overexpressed biomarker related to SIRT1 and PCOS would be a helpful diagnostic tool.2

In obesity and metabolic disorders miRNA-34a binds to 32-UTR of SIRT1 gene and lowers its expression, as SIRT1 activity become dysfunctional, metabolic stress, inflammation and PCOS elevated. 2 We can target miRNA$34 \mathrm{a}$ as a therapeutic factor for PCOS, whereas miRNA 16(decreased expression) and miRNA -222, 146a and Department of Biological and Biomedical Sciences, Aga Khan University, Karachi-Pakistan.

Correspondence: Nida Farooqui. e-mail: nida.farooqui@yahoo.com 30c(increased expression) 3,5 can be used as a possible biomarkers for PCOS diagnosis for further research exploration and can help derive positive results to ease the patients trauma and pain.

Disclaimer: None to declare.

Conflict of Interest: None to declare.

Funding Sources: We received support from Pakistan Science Foundation, PSF/Res/S-AKU/Med(479).

\section{References}

1. Fu X, HeY, Wang X, Peng D, Chen X, Li X, et al. MicroRNA-16 Promotes Ovarian Granulosa Cell Proliferation and Suppresses Apoptosis Through Targeting PDCD4 in Polycystic Ovarian Syndrome. Cell Physiol Biochem 2018; 48: 670-82.

2. Choi SE, Kemper JK. Regulation of SIRT1 by microRNAs. Molecules Cells. 2013; 36: 385-92.

3. Kiyak Caglayan E, Engin-Ustun Y, Gocmen AY, Polat MF, Aktulay A Serum sirtuin 1 levels in patients with polycystic ovary syndrome. J Obstet Gynaecol 2015; 35: 608-11.

4. Christenson LK. MicroRNA control of ovarian function. Animal Reprod 2010; 7: 129-33.

5. Humplikova L, Kollinerova S, Papajik T, Pikalová Z, Holzerová M, Prochazka V, et al. Expression of miR-15a and miR-16-1 in patients with chronic lymphocytic leukemia. Biomedical papers of the Medical Faculty of the University Palacky, Olomouc, Czechoslovakia: 2013;157.

https://doi.org/10.5455/JPMA.59197 